\title{
Taxonomic Probability Matrix for Use With Slowly Growing Mycobacteria
}

\author{
LAWRENCE G. WAYNE, ${ }^{1.2}$ ELAINE J. KRICHEVSKY, ${ }^{3}$ LESLIE L. LOVE, ${ }^{3}$ RAYMOND JOHNSON, ${ }^{4} \dagger$ \\ AND MICAH I. KRICHEVSKY ${ }^{3}$
}

Veterans Administration Medical Center, Long Beach, California $90822^{1}$; Department of Medical Microbiology, California College of Medicine, University of California, Irvine, California $92664^{2}$; Microbial Systematics Section, National Institute of Dental Research, Bethesda, Maryland 20205; and American Type Culture Collection, Rockville, Maryland $20852^{4}$

\begin{abstract}
A probability matrix for identification was developed from data derived from a series of cooperative studies of slowly growing mycobacteria. The matrix includes feature frequencies exhibited by 14 numerical taxonomy clusters in 34 tests. The clusters correspond to 13 defined species. The matrix is designed primarily to screen strains either for membership in 1 of the 14 taxa or for exclusion from these taxa and, thus, to determine whether the strains are in need of further characterization. The matrix was used in the analysis of 298 strains. Two related parameters were used as decision thresholds. First, the probability of the most likely taxon must be 99 times greater than that of the second most likely taxon. Second, the absolute likelihood of the strain being in the most likely taxon must be at least 0.01 times that of a "perfect" strain of the taxon. By using these thresholds and additional judgments, 83 strains were found to be appropriate for further study, with a likelihood that $53 \%$ of these strains belong to unrepresented taxa.
\end{abstract}

The period after the description by Timpe and Runyon (23) of the so-called atypical mycobacteria has been marked by intensive efforts devoted to the taxonomy of the slowly growing mycobacteria. Slow growers are defined as strains requiring 1 week or more for the appearance of visible colonies on solid medium when the inoculum has been diluted sufficiently to yield well-isolated colonies (20). The descriptions of previously recognized species have been expanded, and new species have been proposed. Cooperative studies were carried out by the International Working Group on Mycobacterial Taxonomy (IWGMT), which characterized the most commonly encountered slowly growing mycobacteria in terms of a wide variety of properties (18, 27, 28; H. H. Kleeberg, et al., manuscript in preparation). The species that have been described in these studies, both published and in preparation, include Mycobacterium africanum, $M$. avium, $M$. bovis, $M$. gastri, $M$. gordonae, $M$. intracellulare, $M$. kansasii, $M$. marinum, $M$. microti, $M$. nonchromogenicum, $M$. scrofulaceum, M. terrae, $M$. tuberculosis, and $M$. xenopi. Other species have been proposed, but they have not been encountered as commonly or studied in such detail as those cited above. Undoubtedly, more remain to be discovered.

† Present address: BBL Microbiology Systems, Cockeysville, MD 21030.
A problem facing mycobacterial taxonomists who encounter strains that do not conform perfectly to the description of any known species is the decision as to whether the differences are sufficient to justify the time-consuming studies that would be necessary to establish new taxa. We examined the data derived from the IWGMT cooperative studies in an attempt to select a set of tests that could be employed to help resolve this quandary. Our proposed strategy is based on use of a taxonomic probability matrix, which is defined here as a device to answer whether the properties of a particular strain differ sufficiently from those of any established taxon to justify efforts to generate enough additional data to try to define a new taxon. This is in contrast to a more conventional diagnostic probability matrix, which asks whether the properties of a strain conform sufficiently to those of an established taxon to justify identification of the strain as a member of that taxon.

\section{MATERIALS AND METHODS}

The data used to define the probability matrix were derived from four IWGMT cooperative studies; three of these studies have been published $(18,27,28)$, and one is presently in preparation. The latter, which deals with the $M$. tuberculosis complex, was coordinated by H. H. Kleeberg, who kindly made the raw data available to us. All four of these cooperative studies, representing a total of 298 strains, were focused on slowly 
growing mycobacteria, although a few rapid growers were introduced into the study sets.

Results of immunological tests, phage typing, thinlayer lipid chromatography, and pathogenicity tests were deleted for purposes of this study because these tests require subjective interpretations or specific biological reference materials that are not readily available. The remaining phenotypic data were converted to binary form and coded according to the RKC system (19). The data were entered into the MICRO-IS program at the Microbial Systematics Section, National Institute of Dental Research (12). Irrelevant and "repetitious" data, which were deleted in prior studies (28), were reintroduced into the data pool. Some features that were common to all clusters within any one of the prior studies could provide resolution when the data from all studies were combined; i.e., they were no longer irrelevant. The repetitious data were used to construct modal scores, as described below. In some cases differences in test methods for the same features from different studies would have resulted in additional redundancies. When tables of data were examined with such features presented side by side, it was possible to consolidate some such tests under a single code since the different methods gave equivalent results. In most cases there were multiple entries for a single test code and strain. The modal score (i.e., the result obtained for a given strain by the majority of laboratories performing a given test) was used in the subsequent analysis.

Numerical taxonomy (NT) analyses of the combined data employed simple matching coefficients, with sorting and sequencing according to unweighted average linkage (22). After a preliminary NT run demonstrated that the clustering behavior of strains in the combined pool agreed with that found in the individual studies, 21 strains and a number of tests were deleted by the following criteria to simplify the task of selection of features for a probability matrix.

Some strains appeared in the individual studies as members of clusters composed of fewer than five strains, and most of these were deleted. In addition, six nonpigmented strains of $M$. kansasii were introduced into the study on non-photochromogenic slowly growing mycobacteria (18). Nonpigmented $M$. kansasii strains are encountered only rarely in nature, and inclusion of these strains represented a special selection (for the purpose of the original study) that would have distorted the pigment frequency figures in the probability matrix. Therefore, they were deleted from the data pool used for the final NT analysis, in which cluster borders were defined for generation of the feature frequency table. However, all strains from all studies were reintroduced into the pool when the probability matrix was tested.

In the case of the M. tuberculosis complex IGWMT study, the final analysis had not been completed when this study was carried out. We used all strains from this study for our final NT analysis.

In prior studies, tests were considered most useful if at least $85 \%$ of the strains in one or more clusters were positive and at least $85 \%$ of the strains in one or more of the remaining clusters were negative (18). In the present study, tests that failed to meet this criterion were deleted before we performed the second- stage NT analysis upon which the probability matrix was to be based.

After deletions of strains and tests as described above, we generated the second-stage NT matrix, which was based on 83 features. After establishment of cluster borders, feature frequency lists were generated. This second selection of tests for actual incorporation into a probability matrix was more rigorous than the selection described above. For each test, a difference in frequency of $90 \%$ was required between at least one pair of clusters. At least two such tests were sought to distinguish between any given pair of clusters, although this could not always be achieved. In one case, a test (resistance to $500 \mu \mathrm{g}$ of $p$-nitrobenzoic acid per $\mathrm{ml}$ ) was selected with only an $89 \%$ differential between a pair of clusters. The remaining 33 tests met the $90 \%$ standard.

A probability matrix was constructed from the 34 features and 14 taxa shown in Table 1 . The estimates of probabilities are expressed as percentages of strains giving a positive result. A value of $99 \%$ was given when all of the examined strains of a taxon gave a positive result. Similarly, a value of $1 \%$ was given when the strains of a taxon always gave a negative result. In those cases where data were not available, a value of $50 \%$ was inserted.

The resulting probability matrix was incorporated into an identification program named IDDNEW (7). IDDNEW is part of a group of computer programs that make up a microbial information system (12). IDDNEW is based on a modification of the Bayes Theorem of Probabilities. The logic of the procedure lies in the fact that given independent tests, the probability of obtaining a particular combination of results is the product of the probabilities for obtaining the desired results in each of the tests taken singly. This statistical approach has been used widely in medical diagnosis and more recently in bacteriological studies (4-6, 14, 15, 34, 35).

The likelihood that an unknown strain belongs to any given taxon is defined as the probability of obtaining the observed test results with a strain of this taxon. This probability is found for each taxon by multiplying the probabilities of the individual test results.

The probability values actually used in the computations are decimal scores obtained by dividing the percent positive feature frequencies by 100 . The results returned by the program also are displayed as the decimal probabilities.

When an unknown strain gives a positive result, the probability of the results is taken directly from the matrix. When the result given by an unknown is negative, the probability is found by subtracting the matrix figure from 1.00 (e.g., a 0.01 probability of being positive is equivalent to a 0.99 probability of being negative).

To display clearly the relative values of the likelihoods of the taxa, they are normalized by dividing the likelihood of each taxon by the sum of the likelihoods of all of the taxa. The normalized values are referred to as identification (ID) scores. The best likelihood is defined as the likelihood that each taxon could achieve by using only those test features recorded for the unknown. It is assumed that the results obtained "match" their individual matrix probabilities; 
TABLE 1. Feature frequencies of

\begin{tabular}{|c|c|c|c|c|c|c|c|c|c|c|c|c|c|c|c|}
\hline \multicolumn{16}{|c|}{ Frequency $(\%)$} \\
\hline Cluster & $16250^{a}$ & 16276 & 16264 & 16261 & 16263 & 16315 & 16253 & 16317 & 16089 & 16334 & 98185 & 98220 & 98039 & 17014 & 17035 \\
\hline M. gastri & 8 & 9 & 1 & 92 & 1 & $99^{c}$ & 99 & 1 & 1 & 99 & & & 80 & 99 & 1 \\
\hline M. marinum & 83 & 67 & 67 & 99 & 99 & 99 & & 99 & 17 & & & & & 99 & 1 \\
\hline$M$. kansasii & 11 & 9 & 89 & 97 & 11 & 99 & & 99 & 9 & & & & & 99 & 43 \\
\hline$M$. scrofulaceum & 99 & 30 & 86 & 99 & 85 & 99 & 14 & & 91 & & & & & 99 & 88 \\
\hline$M$. gordonae & 87 & 99 & 88 & 99 & 35 & 99 & 5 & & 60 & & & & & 99 & 6 \\
\hline$M$. xenopi & 1 & 99 & & 86 & 1 & 99 & 29 & 83 & 1 & 99 & & & 99 & 1 & 99 \\
\hline$M$. intracellulare & 97 & 97 & & 99 & 81 & 99 & 99 & 96 & 94 & 99 & & & 83 & & 71 \\
\hline M. avium & 99 & 99 & & 99 & 46 & 99 & 99 & 99 & 83 & 99 & & & 99 & & 92 \\
\hline M. terrae & 99 & 99 & & 99 & 92 & 99 & 99 & 1 & 67 & 99 & & & 91 & 99 & 1 \\
\hline M. nonchromogenicum & 99 & 99 & & 99 & 99 & 99 & 99 & 1 & 50 & 99 & & & 82 & 99 & 33 \\
\hline M. tuberculosis & 4 & & 2 & 1 & 1 & 96 & & & & 2 & 1 & 98 & 10 & & 6 \\
\hline M. microti & 1 & & 1 & 1 & 1 & 1 & & & & 1 & $i$ & 33 & 1 & & 1 \\
\hline M. bovis & 1 & & 8 & 1 & 1 & 1 & & & & 1 & 99 & 1 & 92 & & 1 \\
\hline M. bovis BCG & 1 & & 1 & 1 & 1 & 33 & & & & 1 & 99 & 99 & 1 & & 1 \\
\hline
\end{tabular}

"Feature code number. For definition of features, see Table 2.

"Tests 20018 and 20008 were linked.

"Feature frequencies of $100 \%$ were set equal to $99 \%$; $0 \%$ feature frequencies were set equal to $1 \%$.

i.e., the features are set to positive when the values in the probability matrix are $\geq 0.50$ and are set to negative for values of $<0.50$, and the best likelihood is calculated.

As the program is written, a level of 0.999 is the threshold identification level; i.e., for a strain to be labeled as identified, its ID score must exceed this level. However, as presented below, additional threshold values were used in interpreting the mycobacterial data.

\section{RESULTS}

Probability matrix. The clusters recognized in the NT analyses corresponded to those reported in prior studies $(18,27,28)$. In addition, a first-stage NT analysis performed on the data from the unpublished $M$. tuberculosis complex study (Fig. 1) yielded five major clusters, corresponding to $M$. tuberculosis, $M$. bovis, $M$. bovis BCG, $M$. microti, and $M$. africanum. No attempt is made here to modify the hierarchical standing of any of the taxa studied; clustering was the criterion for generation of the feature frequency table employed, with the understanding that questions of the species versus subspecies status of some clusters may require further resolution.

Although only four strains appeared in the first-stage NT cluster of $M$. microti, a fifth strain (strain 89), which appeared at the bottom of the diagram (Fig. 1), shifted into that cluster in the second-stage NT analysis and was included in the feature frequency calculation for that cluster. On examination of the feature frequency tables, it became evident that three pairs of clusters failed to be differentiated by at least two features with $90 \%$ differences in frequency. An ID score based on best likelihood values for each of these pairs was calculated manually. It was found that a "perfect" strain of $M$. africanum (i.e., one that is identical to the theoretical modal strain) could yield at most an ID score of only 0.9281 because of the great similarity of such a strain to $M$. bovis. Therefore, $M$. africanum was deleted from the probability matrix as a separate taxon. The consequences of this are discussed below. When a similar analysis was performed on the other two problem pairs (M. avium versus $M$. intracellulare and $M$. tuberculosis versus $M$. microt $i$ ), the best-fit ID scores exceeded 0.995 in all cases due to the presence of a sufficient number of lower-level discriminating features; therefore, these taxa were included in the matrix. The probability matrix (Table 1), which incorporated 34 features and 14 taxa (i.e., NT clusters), was tested against all 298 strains. We recognize that it would have been desirable to test an independently studied set of cultures, but no such collection of data was available with sufficient corroboratory NT analyses to permit this to be done. However, the presence of a number of strains that did not fit into any of the selected clusters that were used to generate the feature frequency tables serves a similar function. As discussed below, new IWGMT cooperative studies have been initiated, and these will provide additional strain data for independent confirmation of the matrix.

Reproducibility of the features employed. The effectiveness of a probability program obviously depends upon the reproducibility of the tests employed. The use of composite modal scores in the present study undoubtedly enhanced the quality of the results reported here. A number of the tests used have been 
properties used in probability matrix

\begin{tabular}{|c|c|c|c|c|c|c|c|c|c|c|c|c|c|c|c|c|c|c|}
\hline 17017 & $20018^{b}$ & 20008 & 24424 & 30255 & 30258 & 98282 & 34143 & 30257 & 34123 & 34146 & 34136 & 24425 & 98009 & 34135 & 98030 & 98036 & 98007 & 98010 \\
\hline 1 & 1 & 1 & 1 & 99 & 1 & & 99 & 99 & 1 & 1 & 99 & 1 & 1 & 1 & 99 & 99 & 1 & 8 \\
\hline 1 & 99 & 99 & 1 & 99 & 99 & & 99 & 1 & 1 & 1 & 99 & 99 & 33 & 99 & 99 & 99 & 1 & 1. \\
\hline 1 & 97 & 97 & 1 & 99 & 1 & & 99 & 1 & 1 & 9 & 99 & 99 & 99 & 99 & 99 & 94 & 97 & 14 \\
\hline 1 & 99 & 1 & 1 & 95 & 91 & & 91 & & 1 & 25 & 1 & 99 & 99 & 95 & 1 & 5 & 18 & 23 \\
\hline 1 & 99 & 1 & 1 & 5 & 1 & & 8 & & 1 & 99 & 35 & 99 & 96 & 58 & 91 & 55 & 1 & 67 \\
\hline 99 & 86 & 1 & 1 & 99 & 99 & & 1 & & 1 & 99 & 1 & 99 & 1 & & 1 & 99 & 1 & 57 \\
\hline 63 & 1 & 1 & 1 & 99 & 99 & & 1 & & 4 & 97 & 13 & 97 & 26 & & 1 & 94 & 1 & 91 \\
\hline 1 & 8 & 1 & 1 & 99 & 99 & & 1 & & 1 & 99 & 1 & 50 & 8 & & 1 & 29 & 1 & 23 \\
\hline 1 & 1 & 1 & 1 & 1 & 1 & & 1 & & 92 & 50 & 99 & 99 & 99 & & 99 & 60 & 73 & 83 \\
\hline 1 & 1 & 1 & 1 & 99 & 99 & & 1 & & 99 & 9 & 99 & 99 & 99 & & 99 & 99 & 11 & 46 \\
\hline 1 & 1 & 1 & 99 & 99 & 82 & 94 & 99 & & & 99 & & 2 & 1 & 99 & & & 98 & \\
\hline 1 & 1 & 1 & 99 & 99 & 99 & 99 & 99 & & & 99 & & 1 & 1 & 99 & & & 60 & \\
\hline 1 & 1 & 1 & 1 & 1 & 1 & 1 & 99 & & & 99 & & I & 1 & 99 & & & 8 & \\
\hline 1 & 1 & 1 & 29 & 1 & 14 & 1 & 99 & & & 99 & & 1 & 1 & 99 & & & 86 & \\
\hline
\end{tabular}

examined in IWGMT cooperative studies (32, 33 ) and have been found to be very reproducible; others exhibited less than $90 \%$ reproducibility, and still others have not yet been studied in this manner (Table 2). Furthermore, in these cooperative studies it was found that the degree of reproducibility (i.e., agreement with consensus) differed from laboratory to laboratory. Thus, in some laboratories almost all of the tests can be performed with a high degree of reliability, and successful use of the matrix obviously is predicated on meticulous performance of the tests.

Distribution of strain scores and selection of thresholds. The data for all 298 strains included in the four IWGMT cooperative studies on slowly growing mycobacteria were entered into the probability matrix. Two types of scores were considered in evaluating the efficiency and accuracy of the identification so achieved. The ID score was based on normalization of the sum of the observed likelihood scores. The standard program was designed to consider as definitive a likelihood score for a taxon which was at least 999 times greater than the likelihood for the next closest taxon (i.e., ID score of $>0.999$ ). An example is presented in Fig. 2. When the ID score was below 0.999 , the computer scanned the matrix to determine whether additional tests could be performed which might shift the likelihood values sufficiently to yield an ID score of $>0.999$ (Fig. 3). A second score was calculated as the ratio ( $\mathrm{R}$ score) of the observed likelihood divided by the best possible likelihood when only those features recorded for a given strain were used.

The distribution of the 298 strains according to their most likely taxa and the ID score for those taxa are shown in Table 3. Also included are the numbers of strains with highest ID scores of $<0.999$, for which additional tests were suggested. Among the 194 strains with ID scores of $>0.999,12(6.2 \%)$ did not appear to belong to the indicated taxa, based on their clustering behaviors in the full NT analysis. This was also the case for $3(8.1 \%)$ of the 37 strains with highest ID scores between 0.995 and 0.999 , but it was not the case for any of the nine strains with ID scores between 0.990 and 0.995 . Thus, a threshold of 0.990 did not introduce a higher rate of discrepancy than one of 0.999 (i.e., 6.2 versus $6.3 \%$ ). Of the 27 strains with ID scores below 0.999 , for which additional tests were suggested, $24(89 \%)$ represented disagreements between most likely taxa according to the probability matrix and clustering behavior in a full NT analysis. This is discussed below.

Table 4 shows the distribution of the 271 strains for which no additional tests were suggested, according to their most likely taxa and their $\mathrm{R}$ scores. None of the 86 strains with an $R$ score of 1.0 exhibited a disagreement between most likely taxon and NT clustering behavior. Thereafter, the proportion of disagreements increased as an almost linear inverse function of the $\mathrm{R}$ score. Since a discrepancy in the results of a single test can decrease the $R$ score no more than 99-fold, we decided to accept a threshold $R$ score of 0.01 for further analysis of the data. Of the 219 strains with $\mathrm{R}$ scores equal to or above this value, only 5 (2.3\%) exhibited discrepancies between the most likely taxon and NT clustering.

Based on these decisions, we made an analysis of the distribution of strains according to 


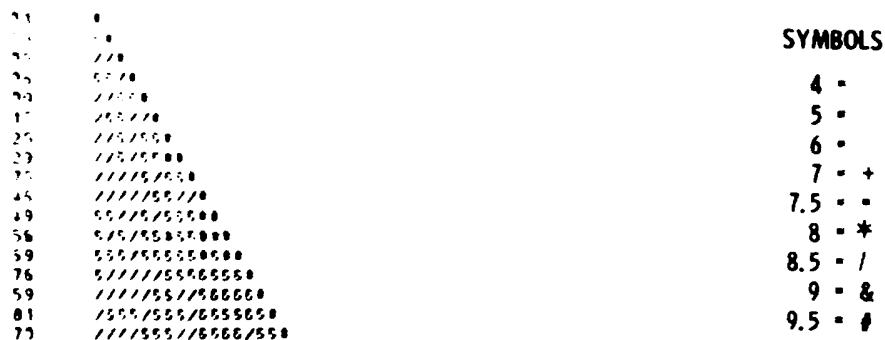

111350115050155

$1 / 55050515858 / 5050$

$50.11051 / 258505850$

$571 / 95 / 18568605650$

$111 / 556 / 180506 / 1 / 51 / 1$
$111 / 3 / 5561 / 66 / 15831 / 10$

$3 / 3 / 5 / 536 / 186 / 1535 / 1,0$

$3,153 / 53 / 68 B 58 / 5635355$

$101 / 3 / 2111111 / 183503550$

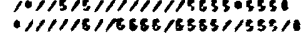

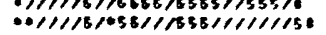

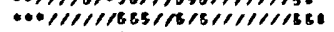

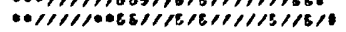

10111111/8e/16s/11111011/8/10

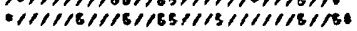

:OA

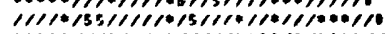

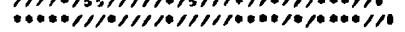

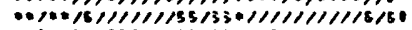

$1 / 5 / 15536586 / 155 / 35 / 5 / 811 / 1 / 1 / 1 / 1 / 80$

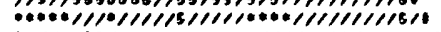

s/11/16s $11111111111111111 / 0+4 / 111110$

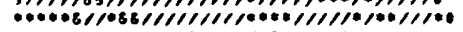

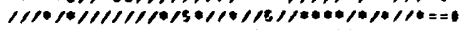

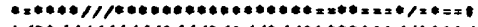

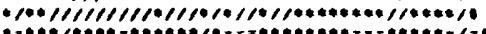

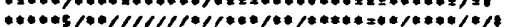

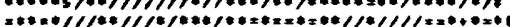

a

no

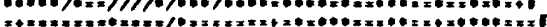

POA

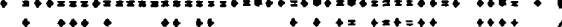

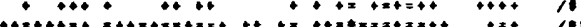

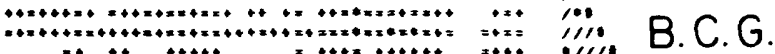

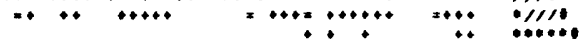

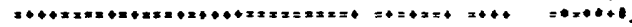

?
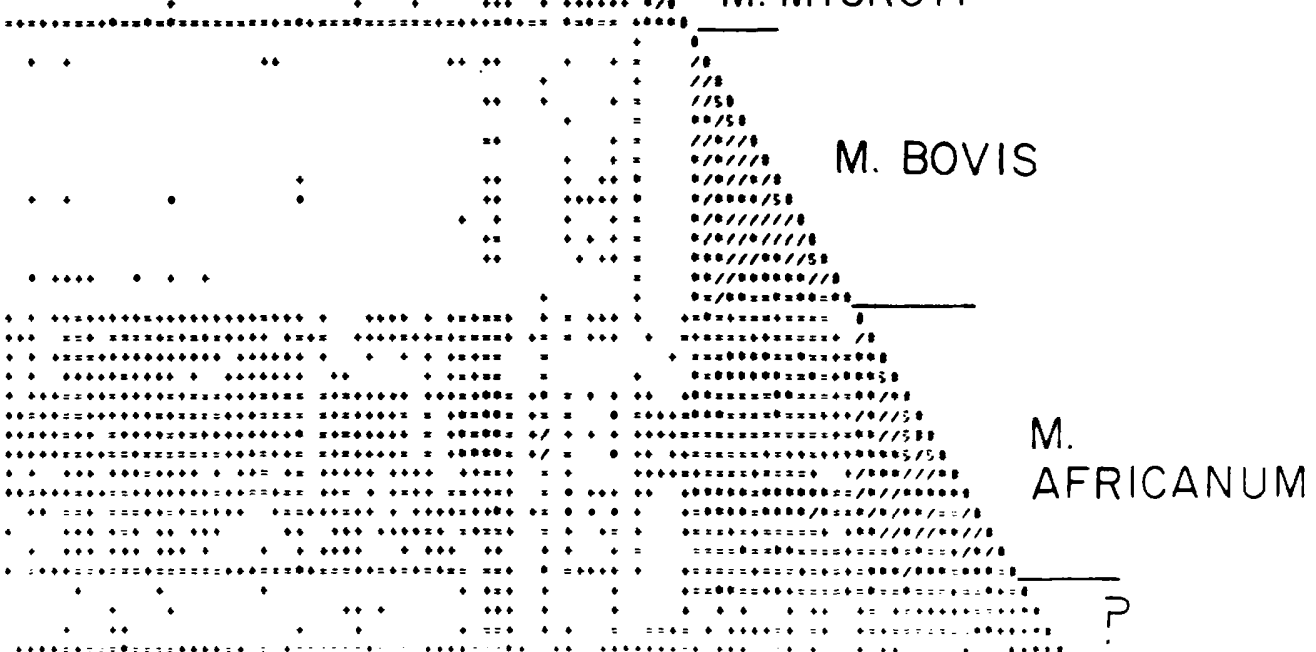

Fig. 1. First-stage NT matrix of strains included in the cooperative study of the M. tuberculosis complex. 
TABLE 2. Reproducibility of and references to techniques for the features employed in the probability matrix

\begin{tabular}{|c|c|c|c|}
\hline Feature & $\begin{array}{l}\text { Feature code } \\
\text { no. (RKC) }\end{array}$ & $\%$ Reproducibility & Reference(s) \\
\hline \multicolumn{4}{|l|}{ Grows in media containing: } \\
\hline Isoniazid $(1 \mu \mathrm{g} / \mathrm{ml})$ & 16250 & 92 & 33 \\
\hline Thiacetazone $(10 \mu \mathrm{g} / \mathrm{ml})$ & 16276 & $90^{a}$ & 33 \\
\hline$p$-Nitrobenzoic acid $(500 \mu \mathrm{g} / \mathrm{ml})$ & 16264 & 91 & 33 \\
\hline Hydroxylamine hydrochloride $(125 \mu \mathrm{g} / \mathrm{ml})$ & 16261 & $\mathrm{ND}^{b}$ & 33 \\
\hline Hydroxylamine hydrochloride $(500 \mu \mathrm{g} / \mathrm{ml})$ & 16263 & $78^{a}$ & 33 \\
\hline Thiophene-2-carboxylic acid hydrazide $(1 \mu \mathrm{g} / \mathrm{ml})$ & 16315 & 97 & 33 \\
\hline$p$-Aminosalicylic acid $(1 \mu \mathrm{g} / \mathrm{ml})$ & 16253 & ND & 33 \\
\hline Ethambutol $(1 \mu \mathrm{g} / \mathrm{ml})$ & 16317 & $86^{a}$ & 33 \\
\hline Oleic acid $(250 \mu \mathrm{g} / \mathrm{ml})$ & 16089 & $82^{a}$ & 31 \\
\hline Toluidine blue $(300 \mu \mathrm{g} / \mathrm{ml})$ & 16334 & ND & 33 \\
\hline Pyrazinamide $(44 \mu \mathrm{g} / \mathrm{ml})$ & 98185 & ND & 17 \\
\hline \multicolumn{4}{|l|}{ Growth characteristics } \\
\hline Stimulated by glycerol & 98220 & ND & 11 \\
\hline Lebek niveau & 98039 & $80^{a}$ & 21 \\
\hline Grows at $25^{\circ} \mathrm{C}$ & 17014 & 87 & 33 \\
\hline Grows at $42^{\circ} \mathrm{C}$ & 17035 & ND & 33 \\
\hline Grows at $45^{\circ} \mathrm{C}$ & 17017 & $88^{\alpha}$ & 33 \\
\hline Photochromogenic & 20008 & 93 & 28 \\
\hline Pigment other than chlorophyll produced & 20018 & 93 & 32 \\
\hline Niacin test & 24424 & 93 & 33 \\
\hline \multicolumn{4}{|l|}{ Enzymatic properties } \\
\hline Nicotinamidase by ammonia assay & 30255 & $88^{a}$ & 1 \\
\hline Pyrazinamidase by ammonia assay & 30258 & $84^{a}$ & 1 \\
\hline Pyrazinamidase by pyrazinoic acid assay & 98282 & ND & 25 \\
\hline Urease by ammonia assay & 34143 & 97 & 32 \\
\hline Propionamidase by ammonia assay & 30257 & ND & 1 \\
\hline$\beta$-Galactosidase & 34123 & 90 & 32 \\
\hline$\alpha$-Esterase & 34146 & $85^{a}$ & 8 \\
\hline Acid phosphatase & 34136 & $86^{a}$ & 9 \\
\hline Catalase resistant to $68^{\circ} \mathrm{C}, 20 \mathrm{~min}$ & 24425 & $87^{a}$ & 13 \\
\hline Catalase activity, $>45 \mathrm{~mm}$ of foam & 98009 & 95 & 33 \\
\hline Peroxidase & 34135 & ND & 24 \\
\hline Tween 80 hydrolysis within 10 days & 98030 & 96 & 32 \\
\hline Aryl sulfatase within 10 days & 98036 & $82^{a}$ & 10 \\
\hline Nitrate reduction moderate & 98007 & $88^{a, c}$ & 2,30 \\
\hline Nitrite reduction $>50 \%$ within 7 days & 98010 & ND & 29 \\
\hline
\end{tabular}

${ }^{a}$ Value derived from one of the two IWGMT cooperative studies on reproducibility of techniques $(32,33)$ but not included in tables or discussion. In the case of susceptibility and growth tests, the techniques described for other drugs in those references would be applicable to the additional agents listed here. For methods for the other tests, see the references cited.

${ }^{b} \mathrm{ND}$, Not determined in a cooperative study.

${ }^{c}$ Moderate nitrate reduction was coded when results were reported as nitrate reduction within $4 \mathrm{~h}$ by a modified Virtanen technique (2) or as $\log$ nitrite value of $>1.4 \mathrm{nmol}$ by the technique of Wayne and Doubek (30).

whether they were above or below either or both of these ID and R score thresholds $(0.990$ and 0.01 , respectively) (Table 5). Of 201 strains which were above both thresholds, only $3(1.5 \%)$ exhibited disagreement between probabilistic identification and NT cluster. On the other hand, $21(30 \%)$ of the 70 strains which fell below one or both thresholds showed such disagreements. In addition, 26 of the 27 strains for which additional tests were suggested were below one or both thresholds. Combining the latter two categories, 45 strains ( $47 \%$ of 96 strains) that were below either or both thresholds exhibited disagreements, and 44 of these did not aggregate into any of the 14 clusters used to generate the matrix. This demonstrated a very striking enrichment of strains likely to belong to taxa other than those represented in the probability matrix. A more detailed analysis of specific categories follows.

Strains exceeding both thresholds: no additional tests suggested. Only 3 of the 201 


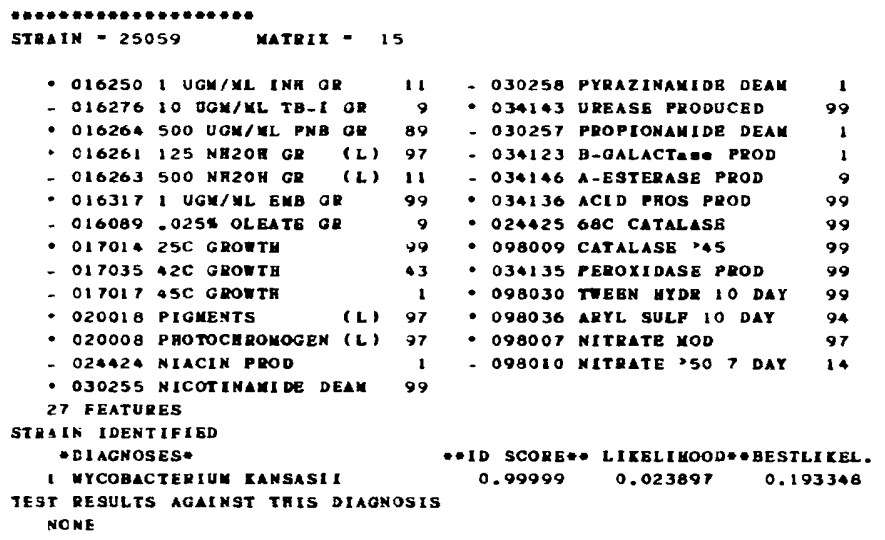

FIG. 2. Example of a report on a strain which has been identified successfully in the probability matrix.

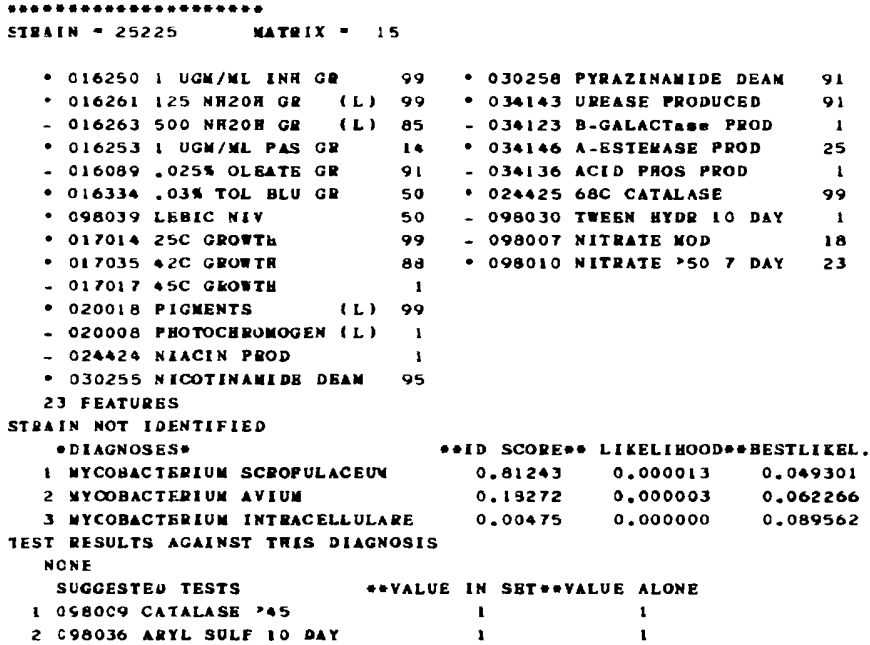

FIG. 3. Example of a report on a strain which has not been identified successfully in the probability matrix and for which additional tests have been suggested.

strains that exceeded both thresholds yielded most likely identifications that were at odds with their NT clustering behaviors. One strain (strain 15975), which was identified as a member of $M$. gordonae, fell in the loose, ill-defined cluster 7 in the first IWGMT NT study (28). Another strain (strain 31), identified as belonging to $M$. microti, fell in the $M$. tuberculosis NT cluster (Fig. 1). The third strain (strain 03), identified as a member of $M$. bovis, fell in the $M$. africanum cluster, which had not been included in the matrix for reasons discussed above.

Strains below either or both thresholds: no additional tests suggested. Of the 70 strains with ID and $\mathrm{R}$ scores below either one or both thresholds, 49 fell into a most likely taxon that agreed with NT clustering behavior. Of these, 11 strains were $M$. kansasii, and all had ID scores above 0.999 but $R$ scores below the threshold. Five of these strains were nonpigmented variants of the species. These five variant strains were included in the studies by virtue of their exotic nature, thus giving them a weight far beyond their frequency of occurrence in nature.

The reverse situation existed for 10 strains of $M$. intracellulare and 4 strains of $M$. avium for which the $\mathrm{R}$ scores were above 0.01 but the ID scores were below the threshold. In each of these cases the sum of the ID scores for $M$. intracellulare and $M$. avium exceeded 0.9999. A significant question has been raised over the validity 
of continued separation of $M$. intracellulare and $M$. avium as different species, since their resolution by NT is equivocal (18). An experienced investigator will recognize the fact that the very close relationship between $M$. avium and $M$. intracellulare is responsible for the low ID scores in the presence of high $\mathrm{R}$ scores and thus will exclude such strains from consideration as new taxa.

Strains for which additional tests were suggested. The identification program employed accepted an ID score of $>0.999$ as defin- itive, so no suggested tests would have been indicated for strains identified at this level. Of 27 strains for which tests were suggested (Table $3), 22$ had ID scores for the most likely taxon that were less than the redefined threshold of $0.990,22$ strains had $R$ scores below a threshold of 0.01 , and only 1 of the 27 strains was above both of these two thresholds. In those cases where the $R$ score was $<0.01$, the addition of the suggested tests could not have changed the interpretation. Even a correct test would have affected the best likelihood and the likelihood

TABLE 3. Frequency distribution of strains according to most likely identification and highest ID score

\begin{tabular}{|c|c|c|c|c|c|c|c|}
\hline \multirow[b]{2}{*}{ Most likely taxon } & \multicolumn{6}{|c|}{ No. of strains with the following ID scores: } & \multirow{2}{*}{$\begin{array}{l}\text { No. of strains } \\
\text { with further } \\
\text { tests proposed }\end{array}$} \\
\hline & $\geq 0.999$ & $\begin{array}{l}<0.999 \text { but } \\
\geq 0.995\end{array}$ & $\begin{array}{l}<0.995 \text { but } \\
\geq 0.990\end{array}$ & $\begin{array}{l}<0.990 \text { but } \\
\geq 0.950\end{array}$ & $\begin{array}{l}<0.950 \text { but } \\
\geq 0.900\end{array}$ & $<0.900$ & \\
\hline M. gastri & 12 & & & & & & \\
\hline M. marinum & 6 & & & & & & \\
\hline M. kansasii & 39 & $1(1)^{a}$ & & & & & $2(2)$ \\
\hline M. scrofulaceum & $26(6)$ & & & & $1(1)$ & $2(2)$ & $4(4)$ \\
\hline M. gordonae & $30(2)$ & & & & & & $2(2)$ \\
\hline M. xenopi & 7 & & & & & & $1(1)$ \\
\hline M. intracellulare & 12 & $7(1)$ & 2 & 3 & 5 & $6(1)$ & \\
\hline M. avium & 2 & 3 & 2 & 3 & 1 & & 1 \\
\hline M. terrae & 12 & & & & & & \\
\hline $\begin{array}{l}\text { M. nonchromo- } \\
\text { genicum }\end{array}$ & 10 & 1 & & & & & $3(3)$ \\
\hline M. tuberculosis & 14 & 24 & 4 & & & 2 & $4(2)$ \\
\hline M. microti & $3(1)$ & $1(1)$ & & $3(1)$ & & $2(1)$ & $3(3)$ \\
\hline M. bovis & $14(3)$ & & 1 & $1(1)$ & & $2(2)$ & $6(6)$ \\
\hline M. bovis BCG & 7 & & & & & & $1(1)$ \\
\hline
\end{tabular}

\footnotetext{
${ }^{a}$ Numbers in parentheses are numbers of strains for which there was disagreement between the most likely identification according to the probability matrix and the actual clustering behavior in a full NT.
}

TABLE 4. Frequency distribution of strains according to the most likely identification and the corresponding likelihood ratio ( $R$ score) ${ }^{a}$

\begin{tabular}{|c|c|c|c|c|c|c|c|}
\hline \multirow[b]{2}{*}{ Most likely taxon } & \multicolumn{7}{|c|}{ No. of strains with the following $\mathrm{R}$ scores: } \\
\hline & $\geq 10^{\circ}$ & $<10^{0}$ but $\geq 10^{-1}$ & $\begin{array}{l}<10^{-1} \text { but } \\
\geq 10^{-2}\end{array}$ & $\begin{array}{l}<10^{-2} \text { but } \\
\geq 10^{-3}\end{array}$ & $\begin{array}{c}<10^{-3} \text { but } \\
\geq 10^{-4}\end{array}$ & $\begin{array}{c}<10^{-4} \text { but } \\
\geq 10^{-5}\end{array}$ & $<10^{-5}$ \\
\hline M. gastri & 9 & & 2 & 1 & & & \\
\hline M. marinum & 1 & 5 & & & & & \\
\hline M. kansasii & 8 & 14 & 6 & 7 & 3 & $2(1)^{b}$ & \\
\hline M. scrofulaceum & 6 & 5 & 6 & $6(3)$ & $2(2)$ & $2(2)$ & $2(2)$ \\
\hline$M$. gordonae & 3 & 14 & $7(1)$ & 3 & 1 & $2(1)$ & \\
\hline M. xenopi & 2 & 4 & 1 & & & & \\
\hline$M$. intracellulare & 6 & $12(1)$ & 9 & 6 & & 1 & $1(1)$ \\
\hline M. avium & 5 & 5 & 1 & & & & \\
\hline M. terrae & 3 & 5 & 4 & & & & \\
\hline $\begin{array}{l}\text { M. nonchromogeni- } \\
\text { cum }\end{array}$ & 3 & 7 & & 1 & & & \\
\hline M. tuberculosis & 27 & 7 & 5 & 3 & 2 & & \\
\hline M. microti & 2 & $4(1)$ & $1(1)$ & & $1(1)$ & $1(1)$ & \\
\hline$M$. bovis & 9 & & $4(1)$ & & $2(2)$ & $3(3)$ & \\
\hline M. bovis $\mathrm{BCG}$ & 2 & 4 & 1 & & & & \\
\hline
\end{tabular}

\footnotetext{
${ }^{a} \mathrm{R}$ score is defined as the ratio of observed likelihood to best likelihood for the most likely taxon on the battery of features recorded for a given strain.

${ }^{b}$ For explanation of numbers in parentheses, see Table 3 , footnote ${ }^{a}$.
} 
TABLE 5. Frequency distribution of strains according to most likely identification and values relative to selected threshold levels for ID and $R$ scores ${ }^{a}$

\begin{tabular}{|c|c|c|c|c|}
\hline \multirow{2}{*}{ Most likely taxon } & \multicolumn{3}{|c|}{$\begin{array}{l}\text { No. of strains with diagnoses below one or both of the following } \\
\text { thresholds: }\end{array}$} & \multirow{2}{*}{$\begin{array}{l}\text { No. of strains with } \\
\text { diagnoses above both } \\
\text { thresholds }\end{array}$} \\
\hline & ID $<0.990, R \geq 0.01$ & ID $\geq 0.990, R<0.01$ & ID $<0.990, \mathrm{R}<0.01$ & \\
\hline M. gastri & & 1 & & 11 \\
\hline M. marinum & & & & 6 \\
\hline M. kansasii & & $12(1)^{b}$ & & 28 \\
\hline M. scrofulaceum & & $9(6)$ & $3(3)$ & 17 \\
\hline M. gordonae & & $6(1)$ & & $24(1)$ \\
\hline M. xenopi & & & & 7 \\
\hline M. intracellulare & $11(1)$ & $4(1)$ & 4 & 16 \\
\hline M. avium & 4 & & & 7 \\
\hline M. terrae & & & & 12 \\
\hline$M$. nonchromogenicum & & 1 & & 10 \\
\hline M. tuberculosis & & 2 & 2 & 40 \\
\hline M. microti & $4(1)$ & $1(1)$ & $1(1)$ & $3(1)$ \\
\hline M. bovis & & $2(2)$ & $3(3)$ & $13(1)$ \\
\hline M. bovis $\mathrm{BCG}$ & & & & 7 \\
\hline
\end{tabular}

\footnotetext{
" $\mathrm{R}$ score is defined in Table 4 , footnote $a$.

${ }^{b}$ For explanation of numbers in parentheses, see Table 3 , footnote ${ }^{a}$.
}

scores equally and thus would not have changed the value of the $R$ score. For those strains which exhibited an R score of $>0.01$ and a low ID score, the addition of a single suggested test could have depressed the ID score of the second most likely taxon by as much as 100 -fold, thus causing a shift above threshold for the higher ID score. The maximum effect of adding the sole suggested test for the four strains that fell into this category was calculated by assuming that the result of the suggested test would have been in accord with the most likely taxon and by recalculating the ID score. For three strains, this calculation shifted the ID score above the 0.990 threshold. In one case, the identification so achieved (M. tuberculosis) agreed with the NT clustering behavior of the strain; in the other two cases, the definitive diagnoses $(M$. bovis and $M$. bovis BCG) disagreed with the NT clustering. However, both of these strains occupied a position in the general region of $M$. bovis. Of the remaining 22 strains (i.e., those witn $R$ scores of $<0.01$ ) which could not have been raised above the threshold by the addition of the suggested test(s), 21 fell into NT clusters or isolated positions that did not correspond to any of the taxa defined in the probability matrix; thus, these would be appropriate candidates for further taxonomic exploration. One strain with an adjusted ID score (based on one suggested test) for $M$. xenopi of 0.99812 and an $\mathrm{R}$ score of 0.000032 was received with that label, but some of the participants in the study had reported it to be a mixed culture (18). The one strain that exceeded both thresholds was identified as belonging to $M$. gordonae, but it showed a relatively high affinity for both the $M$. gordonae and the $M$. scrofulaceum clusters in the NT analysis.

Observation on members of the $M$. tuberculosis complex. On inspection of the feature frequency table (Table 1), it is evident that there was a greater difference between the features selected by participants in the cooperative study of the $M$. tuberculosis complex (i.e., $M$. tuberculosis, $M$. microti, $M$. bovis, $M$. bovis BCG, and $M$. africanum) and the other three studies than among features selected for each of these other studies, from which the data pool was derived. This reflects a selection of tests that the participants believed would provide maximal resolution within this complex. For this reason it is not possible to ascribe the same hierarchical status to clusters coming from different studies. The sharp delineation of the $M$. bovis BCG strains, both as an NT cluster and as a clearly identifiable probability group, is especially noteworthy in this regard. These strains were all derived, over a period of many decades, from a nonpathogenic variant of $M$. bovis. This suggests that some of the clustering seen within this complex might be most appropriately interpreted in subspecific or infrasubspecific terms, as defined in the International Code of Nomenclature of Bacteria (16).

For reasons discussed above, $M$. africanum was not included in the probability matrix. As a consequence, strains that fell into this poorly defined cluster (Fig. 1) were categorized as most like $M$. microti or $M$. bovis. However, the $\mathrm{R}$ scores for all 14 of these strains were well below the threshold value, as were the ID scores of 11 of them. It is noteworthy that an independent 
N'T analysis of strains identified as members of $M$. africanum failed to demonstrate a distinct cluster for these strains (3). The results of the present probability analysis indicate that further work is needed before this taxon can be either supported or rejected with assurance.

\section{DISCUSSION}

The taxonomic probability matrix described here is not intended to be used to define new taxa. It is designed to be used as part of a screening strategy to help investigators select from a large number of strains those few which might be candidates for new taxon status and thus to justify the great amount of work required to establish new taxa in a convincing way. The judgment and experience of an investigator are still the essential ingredients in this decisionmaking process. Thus, selection on the basis of the two threshold scores proposed served to eliminate 201 of 298 strains from consideration as representing new taxa, with the attendant failure to recognize only 3 strains that might have been candidates for further study. Actually, only one of these (strain 15975) appears to have been a significant candidate. Exclusion of the 14 subthreshold strains of $\boldsymbol{M}$. avium and $\boldsymbol{M}$. intracellulare from the 97 recognized candidates leaves 83 strains selected for detailed study, with a likelihood that $53 \%$ of them represent taxa not included in the matrix.

A number of additional species of slowly growing mycobacteria have been reported, but insufficient data were available to generate reliable feature frequency tables for them. An openended cooperative study on strains that do not conform to the taxa reported here has been initiated by the IWGMT. It is anticipated that the data generated will permit the addition of more of the presently recognized species to the matrix and will also permit NT recognition of previously unreported taxa.

It should be noted that it is not necessary to have data on all 34 of the listed features for a strain in order to employ the probability matrix. In most cases a partial set of data can indicate (by the $\mathrm{R}$ score) if a strain is so unlike any taxon in the matrix as to be a reasonable candidate for intensive study and whether a sufficient number of features have been recorded to resolve between two similar possibilities (by the ID score). The mean number of available features for the 298 strains reported here was 23 . The presence of all 34 features in the matrir nakes it easier to accommodate additional specie's as full descriptions become available.

An appropriate strategy for evaluating a strain is to enter the data already available (e.g., from a clinical laboratory) into the computer. If the results exceed both thresholds, the strain is identified and thus excluded from further analysis. If the $\mathrm{R}$ score is $>0.01$ but the ID score is $<0.99$, the additional suggested tests should be performed. If the strain is still below either threshold, it should be subjected to a full taxonomic analysis as a candidate for possible new taxon status.

In any case, before a new taxon is proposed, it is highly advisable to confirm the unique character of its members, not only by NT analysis but also by independent confirmatory properties, such as nucleic acid homology, immunological distance measurement or electrophoretic pattern determination of selected proteins, and/ or antigenic analyses (26). Furthermore, sufficient numbers of members of a new taxon should be examined to permit feature frequency tables to be prepared, thus permitting entry of the new taxon into some form of descriptive matrix, such as the one described here.

\section{REPRINT REQUESTS}

Address reprint requests to: Dr. Lawrence G. Wayne, Veterans Administration Hospital, 5901 East Seventh Street, Long Beach, CA 90822.

\section{LTERATURE CITED}

1. Bönicke, R. 1962. Identification of mycobacteria by biochemical methods. Bull. Int. Union Tuberc. 32:13-68.

2. Bönicke, R., E. Rohrscheidt, and E. Pascoe. 1962. Die Verbreitung der Nitratreduktase innerhalb der Gattung Mycobacterium. Sonderdr. Naturwiss. 49:43-44.

3. David, H. L., M. Jahan, A. Jumen, J. Grandy, and E. H. Lehman. 1978. Numerical taxonomy analysis of Mycobacterium africanum. Int. J. Syst. Bacteriol. 28: 412-472.

4. Dybowski, W., and D. A. Franklin. 1968. Conditional probability and the identification of bacteria: a pilot study. J. Gen. Microbiol. 54:215-229.

5. Friedman, R. B., D. Bruce, J. Maclowry, and V. Brenner. 1973. Computer-assisted identification of bacteria. Am. J. Clin. Pathol. 60:395-403.

6. Friedman, R., and J. Maclowry. 1973. Computer identification of bacteria on the basis of their antibiotic susceptibility patterns. Appl. Microbiol. 26:314-317.

7. Johnson, R. 1979. Computer-aided identification. FDA (Food Drug Adm.) By-Lines 9:235-250.

8. Käppler, W. 1965. Acetyl-naphthylamin-esterasen-aktivität von Mykobakterien. Beitr. Klin. Tuberk. 130:1-4.

9. Käppler, W. 1965. Zur Differanzierung von Mykobakterien mit dem Phosphatase-Test. Beitr. Klin. Tuberk. Spezifischen Tuberk. Forsch. 130:223-226.

10. Käppler, W. 1968. Zur Taxonomie der Gattung Mycobacterium. I. Klassifizierung schnell wachsender Mykobakterien. Z. Tuberk. 129:311-319.

11. Käppler, W. 1971. Beitrag zur Artbestimmung von Mykobakterien. Z. Erkr. Atmungsorgane 135:39-51.

12. Krichevsky, M. I. 1979. The microbial information system (MICRO-IS): a system overview. FDA (Food Drug Adm.) By-Lines 9:217-222.

13. Kubica, G. P., and G. L. Pool. 1960. Studies on catalase activity of acid-fast bacilli. Am. Rev. Respir. Dis. 81: 387-391.

14. Lapage, S. P., S. Bascomb, W. R. Willcox, and M. A. 
Curtis. 1970. Computer identificaton of bacteria, p. 122. In A. Baillie and R. J. Gilbert (ed.), Automation, mechanization and data handling in microbiology, Academic Press, Inc., London.

15. Lapage, S. P., S. Bascomb, W. R. Willcox, and M. A. Curtis. 1973. Identification of bacteria by computer: general aspects and perspectives. J. Gen. Microbiol. 77: 273-290.

16. Lapage, S. P., P. H. A. Sneath, E. F. Lessel, V. B. D. Skerman, H. P. R. Seeliger, and W. A. Clark (ed.). 1975. International code of nomenclature of bacteria, 1976 revision. American Society for Microbiology, Washington, D.C.

17. Marks, J. 1964. A stepped pH technique for the estimation of pyrazinamide sensitivity. Tubercle 45:47-50.

18. Meissner, G., K. H. Schröder, G. E. Amadio, W. Anz, S. Chaparas, H. W. B. Engel, P. A. Jenkins, W. Käppler, H. H. Kleeberg, E. Kubala, M. Kubin, D. Lauterbach, A. Lind, M. Magnusson, Z. Mikova, S. R. Pattyn, W. B. Schaefer, J. L. Stanford, M. Tsukmura, L. G. Wayne, I. Willers, and E. Wolinsky. 1974. A cooperative numerical analysis of nonscotoand nonphotochromogenic slowly growing mycobacteria. J. Gen. Microbiol. 83:207-235.

19. Rogosa, M., M. I. Krichevsky, and R. Colwell. 1971. Method for coding data on microbial strains for computers (edition AB). Int. J. Syst. Bacteriol. 21:1 A-175A.

20. Runyon, E. H., L. G. Wayne, and G. P. Kubica. 1974. Family II. Mycobacteriaceae Chester 1897, 63, p. 681701. In R. E. Buchanan and N. E. Gibbons (ed.), Bergey's manual of determinative bacteriology, 8 th ed. The Williams \& Wilkins Co., Baltimore.

21. Schmiedel, A., and W. Gerloff. 1965. Dreifach-differenzierung von Mykobacterien in der Agar-HohenSchicht-Kultur. Prax. Pneumol. 19:528-536.

22. Sneath, P. H. A., and R. R. Sokal. 1973. Numerical taxonomy. W. H. Freeman and Co., San Francisco.

23. Timpe, A., and E. H. Runyon. 1954. The relationship of "atypical" acid-fast bacteria to human disease. J. Lab. Clin. Med. 44:202-209.

24. Tirunarayanan, M. O., W. A. Vischer, and H. Bruhin. 1960. Some properties of catechol peroxidase of mycobacteria bearing on isoniazid susceptibility. J. Bacteriol. 80:423-429.

25. Wayne, L. G. 1974. Simple pyrazinamidase and urease tests for routine identification of mycobacteria. Am. Rev. Respir. Dis. 109:147-151.

26. Wayne, L. G. 1978. Mycobacterial taxonomy: a search for discontinuities. Ann. Inst. Pasteur Paris 129A:13-27.

27. Wayne, L. G., L. Andrade, S. Froman, W. Käppler, E. Kubala, G. Meissner, and M. Tsukamura. 1978.
A cooperative numerical analysis of Mycobacterium gastri, Mycobacterium kansasii and Mycobacterium marinum. J. Gen. Microbiol. 109:319-327.

28. Wayne, L. G., T. M. Dietz, C. Gernez-Rieux, P. A. Jenkins, W. Käppler, G. P. Kubica, J. B. G. Kwapinski, G. Meissner, S. R. Pattyn, E. H. Runyon, K. H. Schröder, V. A. Silcox, A. Tacquet, M. Tsukamura, and E. Wolinsky. 1974. A cooperative numerical analysis of scotochromogenic slowly growing mycobacteria. J. Gen. Microbiol. 66:255-271.

29. Wayne, L. G., and J. R. Doubek. 1965. Classification and identification of mycobacteria. II. Tests employing nitrate and nitrite as substrate. Am. Rev. Respir. Dis. 91:738-745.

30. Wayne, L. G., and J. R. Doubek. 1968. Diagnostic key to mycobacteria encountered in clinical laboratories Appl. Microbiol. 16:925-931.

31. Wayne, L. G., J. R. Doubek, and R. Russell. 1964 Classification and identification of mycobacteria. I. Tests employing Tween 80 as substrate. Am. Rev. Respir. Dis. 90:588-597.

32. Wayne, L. G., H. C. Engbaek, H. W. B. Engel, S. Froman, W. Gross, J. Hawkins, W. Käppler, A. G. Karlson, H. H. Kleeberg, I. Krasnow, G. P. Kubica, C. McDurmont, E. E. Nel, S. R. Pattyn, K. H Schröder, S. Showalter, I. Tarnok, M. Tsukamura, B. Vergmann, and E. Wolinsky. 1974. Highly reproducible techniques for use in systematic bacteriology in the genus Mycobacterium: tests for pigment, urease, resistance to sodium chloride, hydrolysis of Tween $\mathbf{8 0}$ and $\beta$-galactosidase. Int. J. Syst. Bacteriol. 24:412-419.

33. Wayne, I. G., H. W. B. Engel, C. Grassi, W. Gross, J. Hawkins, P. A. Jenkins, W. Käppler, H. H. Kleeberg, I. Krasnow, E. E. Nel, S. R. Pattyn, P. A. Richards, S. Showalter, M. Slosarek, I. Szabo, I. Tarnok, M. Toukamura, B. Vergmann, and E. Wolinsky. 1976. Highly reproducible techniques for use in systematic bacteriology in the genus Mycobacterium: tests for niacin and catalase and for resistance to isoniaxid, thiophene 2-carboxylic acid hydrazide, hydroxylamine, and p-nitrobenzoate. Int. J. Syst. Bacteriol. 26: 311-318.

34. Willcox, W. R., and S. P. Lapage. 1975. Methods used in a program for computer-aided identification of bacteria, p. 103-119. In R. J. Pankhurst (ed.), Biological identification with computers. Academic Press, Inc., London.

35. Willcox, W. R., S. P. Lapage, S. Bascomb, and M. A. Curtis. 1973. Identification of bacteria by computer: theory and programming. J. Gen. Microbiol. 77:317330 . 